\title{
Antimicrobial Peptide
}

National Cancer Institute

\section{Source}

National Cancer Institute. Antimicrobial Peptide. NCI Thesaurus. Code C123795.

A natural or synthetically-derived peptide that selectively kills or inhibits the growth of microorganisms; it may also have immunomodulatory activity. 